\title{
Social Perceptions in Computer Science and Implications for Diverse Students*
}

\author{
Jennifer Wang \\ Google, Inc. \\ 1600 Amphitheatre Pkwy. \\ Mountain View, CA 94043 USA \\ jtw@google.com
}

\author{
Sepehr Hejazi Moghadam \\ Google, Inc. \\ 1600 Amphitheatre Pkwy. \\ Mountain View, CA 94043 USA \\ shmoghadam@google.com
}

\author{
Juliet Tiffany-Morales \\ Google, Inc. \\ 1600 Amphitheatre Pkwy. \\ Mountain View, CA 94043 USA \\ jtmorales@google.com
}

\begin{abstract}
The barriers to diversity in computer science (CS) are complex, consisting of both structural and social barriers. In this paper, we focus on social perceptions for students in grades 7-12 in the U.S. using surveys of nationally representative samples of 1,672 students, 1,677 parents, 1,008 teachers, 9,805 principals, and 2,307 superintendents. Building on qualitative work by Lewis, Anderson, and Yasuhara [1,2], we sought to understand social beliefs regarding students' fit and ability as well the external context. We examined these factors' relationships to students' interest. The results are consistent with the current body of research on gender differences in social perceptions in CS. They also identify new findings for race/ethnicity, specifically Black and Hispanic students. As K-12 CS expands, these findings could inform differentiation strategies in equitably engaging students.
\end{abstract}

\section{KEYWORDS}

Race; ethnicity; gender; Black; African American; Hispanic; Latinx; females; girls; women; K-12; pre-university; middle school; high school; perceptions; ability; mindset; confidence; fit; identity; media; encouragement; parents; teachers; interest

\section{INTRODUCTION}

Efforts to broaden access to $\mathrm{K}-12 /$ pre-university computer science (CS) have gained tremendous traction and momentum in recent years. Despite these efforts, underrepresentation of certain demographics persists at this level.

Our previous study found that between 2014-15 and 2015-16, the percentage of U.S. K-12 principals who said they offered CS classes with programming increased from $25 \%$ to $40 \%$ [3]. This increase in overall access, however, does not guarantee a similar improvement in equity of access. As demonstrated in the extensive qualitative study by Margolis et al. [4], even when

"Permission to make digital or hard copies of part or all of this work for personal or classroom use is granted without fee provided that copies are not made or distributed for profit or commercial advantage and that copies bear this notice and the full citation on the first page. Copyrights for third-party components of this work must be honored. For all other uses, contact the Owner/Author.

ICER '17, August 18-20, 2017, Tacoma, WA, USA

(C) 2017 Copyright is held by the owner/author(s).

ACM ISBN 978-1-4503-4968-0/17/08.

http://dx.doi.org/10.1145/3105726.3106175 advanced CS courses are available in school, students of color may not be participating in them.

Through our national surveys, we probe the social factors that may be influencing students to not participate in CS, providing quantitative and representative data on U.S. students. In particular, we aim to explore factors that could be holding back students who may have access to CS opportunities. Moving beyond structural access, we dive into social perceptions around fit and ability [1,2], and investigate differences by race/ethnicity and gender from both the intervening perspectives through students and the external context through parents' and educators' perspectives. Our primary research goal is to determine how pervading social perceptions play out for students of various demographics, specifically females compared to males, and between Black, Hispanic, and White students, and these factors' relationships with students' interest in learning CS.

We hope that our findings can help move us beyond just offering CS as the ultimate solution and towards truly ensuring that all students are enabled to learn CS. As we see, however, social perceptions play out differently for each demographic, which are further complicated by variations within each group.

\section{LITERATURE}

We build on a large body of work in CS education research, particularly those investigating issues related to underrepresentation for Black and Hispanic students and for girls. Our work contributes new findings to the research on race/ethnicity and confirms much of the research on gender in $\mathrm{CS}$ education. In particular, we contribute new knowledge on pre-university students and related social perceptions.

Little prior research has explored identity in CS with specific focus on race/ethnicity. However, previous research has shown that Black and Hispanic students have been found to be less likely to know an adult in the tech industry, compared to White or Asian students [5]. We contribute to research exploring identity in CS.

Previous studies have also identified interest in technology among Black/African American and Hispanic/Latinx youth and parents. For instance, Colby et al. [5] found that Black and Hispanic students have a more positive perception of the CS field, compared to White and Asian students. Rideout, Scott, and Clark [6] also found that there is high interest among Black youth to learn how to do new activities on the computer, and their parents think that "being good at computers" is important to their children's career and education. Interest in CS among 
students and parents, however, has not been broadly explored for differences by race/ethnicity, which we investigate in this paper.

Prior research has found that lack of CS exposure is possibly a large reason for the dearth of knowledge and encouragement [7] and prior experience is one of the most important predictors of computer attitudes [8] while other studies have found that students without prior experience identified CS as more broadly meaningful [e.g., 9].

For confidence, differences by race/ethnicity may not be as consistent with representation in CS. For instance, Blacks and Hispanics have been found to be more likely than Whites or Asians to say that they would be good at working with computers [5]. On the other hand, Margolis et al. found that Hispanic students have low confidence [4]. Exposure to computers may also be important, as experience with computers has been found to positively affect confidence and attitudes $[8,10]$. This is especially relevant as Black and Hispanic students are less likely to have exposure to computers at home and school [3].

There is conflicting research on whether identifying with people who engage in CS, in particular stereotypes, promotes interest in CS [1]. While only a small segment of the research focusing on gender is directly related to identity, Cheryan et al. propose that masculinity in CS is a large deterrent for girls [11]. Another study finds that females are 2.5 times as likely as males to say that people in tech are "boring" and "not like me" [5]. Other studies [1,12-14] further found that girls are more likely to see CS as asocial, competitive, and individualistic. Girls are also less likely to be aware and have knowledge of CS [7].

Given these factors, it is not surprising that many studies have found that interest in computers is lower among girls than boys [15]. In particular, boys are more likely to have chosen to learn $\mathrm{CS}$, through playing with computers and participating in computing activities [15-20]. Females have generally less favorable attitudes towards CS and STEM [20,21]. Our paper contributes a broad quantitative exploration of interest in CS with nationally representative students.

Prior studies have also found that girls have lower confidence than boys, particularly in STEM and CS. For example, even when teachers rated boys and girls equally competent or test scores were similar among boys and girls, boys were more likely than girls to indicate self-efficacy and confidence [21,22]. Other studies in after-school contexts with different ages consistently demonstrate lower confidence among girls [15,16,23,24].

The following sections provide the details of our large-scale national study, describe the extent to which our results confirm the existing literature, and attempt to contribute new insights on differences between races/ethnicities.

\section{THEORETICAL FRAMEWORK}

In late 2015-early 2016, we conducted national surveys of U.S. students, parents, teachers, principals and superintendents as part of a study on the status of CS education in the U.S. Details on the methodology are in the next section. Here, we describe the theoretical framework for the analyses in this paper.
Our resulting descriptive statistics are intended to fill a critical need for national data on the diversity gaps in CS in the U.S. With such a rich source of national data, we investigated how these data might be analyzed to add to the field's understanding of the status of CS education in the U.S., particularly for the underrepresented populations of Black students, Hispanic students, and girls.

We build on a framework from Lewis, Yasuhara, and Anderson, who interviewed college students in introductory CS courses about their decision-making process for choosing to major or not major in CS [1,2]. The authors identified five "interrelated factors" students consider in their process including: ability, enjoyment, fit, utility, and opportunity costs. They explore two of the five factors-ability and fit-and offer theoretical frameworks for understanding how students go about assessing their CS ability and fit [1,2].

Lewis et al. [2] posit that college students go through a twostage process of self-assessment when determining whether or not they have the ability to major in CS. In the first stage, students measure their own ability (central phenomenon) based on "uninterpreted measurements of ability" (e.g., grades in CS courses) and consider the culture and environment in which they will be learning CS (referred to as external context). Lewis et al. also suggest that in this first stage, students' "mindsets" impact their assessment of their CS ability (referred to as intervening conditions). For example, students with a "fixed mindset" believe that intelligence or ability is fixed or innate whereas students with a "growth mindset" believe that intelligence or ability is something that can be built on or increased with effort. In the second stage of the self-assessment process, students evaluated their ability by interpreting the meaning of measurements (e.g., relevance of their CS experience to the CS major, benchmarking grades with peers at similar CS experience levels - rather than comparing grades against the entire class).

Lewis et al.'s theoretical framework surfaced the question of whether our national survey data measured components of this two-stage process of self-assessment at the middle and high school level. An analysis of our national survey questions found several questions mapped to the first stage of assessing CS ability. These include questions on confidence and selfassessment, which represent intervening conditions influenced by their "mindsets," as measured by our survey question on the perception of the need to be "smart." We also found several survey items that measure identity aligned to CS, a component of fit outlined in Lewis et al. [2]. These include questions on students' perceptions of their skills in various subjects as well as their agreement with positive statements of CS careers. We also include a question on how students identify with representations of CS in the media. The third input we explored was the external social context, which include questions on exposure and encouragement, as well as parent survey questions on factors that may influence their encouragement of their children. See Table 1 for a crosswalk of the theoretical framework components and national survey items. 
Table 1: Crosswalk of Theoretical Framework with Our Study's National Survey Items

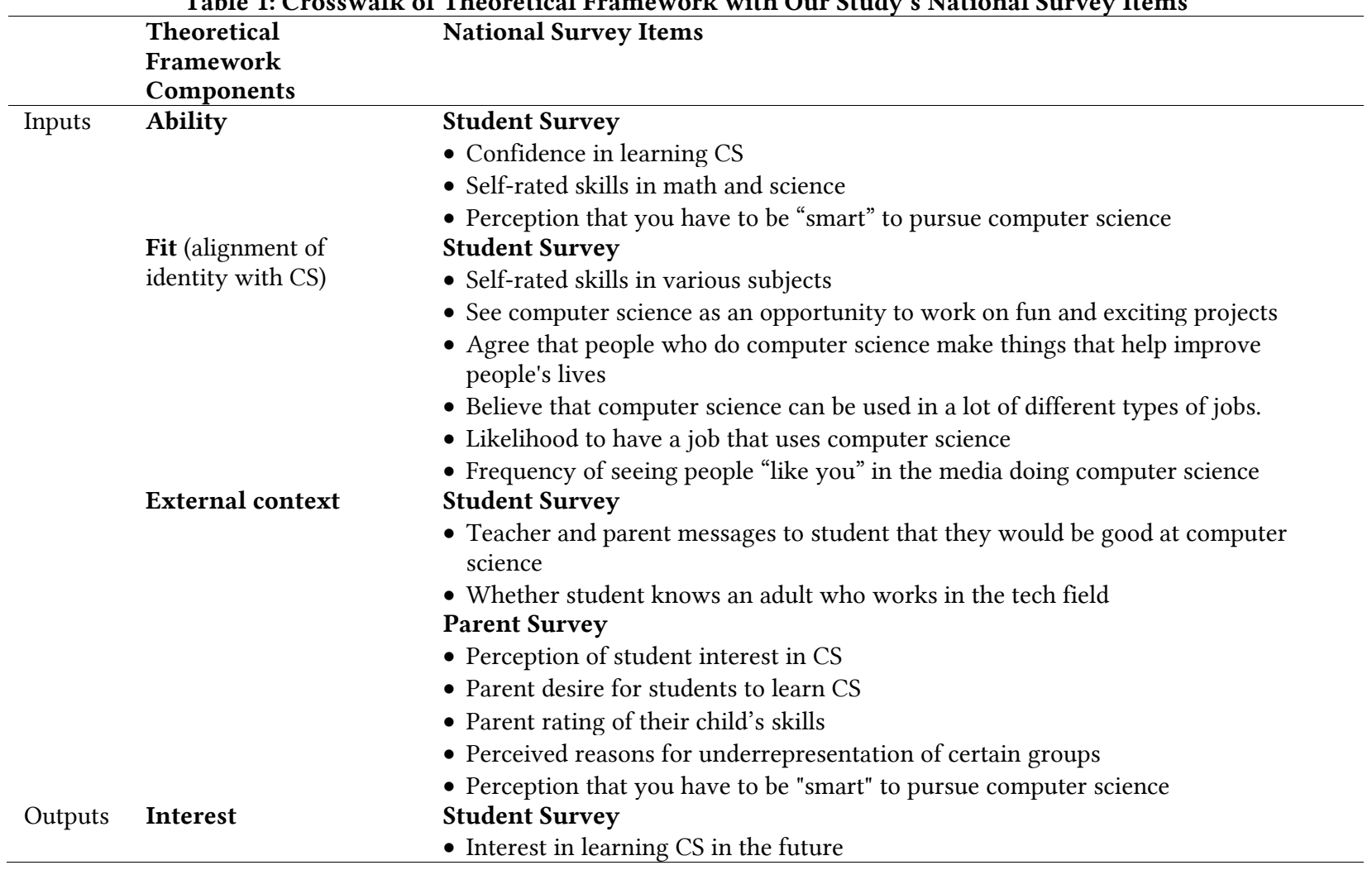

Lewis et al.'s theoretical frameworks [1,2] provide a foundation to investigate the extent to which middle and high school students in our study reported positive self-assessments of CS ability and fit, along with external context. We use the frameworks to explore the relationship between these factors and interest in pursuing CS.

\section{METHODS}

This two-year study surveyed about 16,000 students, parents, teachers, principals, and superintendents each year across the United States. Table 2 shows the mode and respondents for the study. These populations were selected to understand social perceptions from students and the external context through parents and educators (influencers in the students' education). This paper focuses on findings from the second year of the study.

Gallup Inc. conducted telephone surveys with students, parents, and teachers currently living in all 50 states and the District of Columbia using a combination of the Gallup Panel and the Gallup Daily tracking survey. The Gallup Panel is a probability-based panel of U.S. adults selected using randomdigit-dial (RDD) and address-based sampling methods. The Gallup Panel is not an opt-in panel. The Gallup Daily tracking survey sample includes national adults with a quota of $50 \%$ cellphone and $50 \%$ landline respondents, with additional minimum quotas by time zone within region. Landline and cellphone numbers are selected using RDD methods. Landline respondents are chosen at random within each household based on which member had the most recent birthday. Eligible Gallup Daily tracking respondents who previously agreed to future contact were contacted to participate in this study.

Student and parent samples included targeted, detailed data on underrepresented populations (Blacks and Hispanics, including Spanish-speaking only). All Hispanic students are categorized as Hispanic in this study. Non-Hispanic Black students and nonHispanic White students are categorized as Black and White, respectively. Participating students were from grades 7-12 (typically ages 12-18). Participating parents had one or more children in these grades. Teachers in the sample taught 1st-12th grade, with approximately $21 \%$ teaching or have taught computer science. The population for principals was sampled from a list of $99 \%$ of U.S. public schools and approximately $30 \%$ of U.S. private schools. The population for superintendents was from a panel including more than $20 \%$ of all U.S. K-12 superintendents.

Table 2: Methodology overview for the five populations.

\begin{tabular}{lccl}
\hline Population & Mode & Grades & Sample Year 2 \\
\hline Students & Phone & $7-12$ & 1,672, including \\
& & & $\bullet 228$ Black \\
& & & $\bullet 310$ Hispanic \\
Parents & Phone & $7-12$ & 1,677, including \\
& & & $\bullet 197$ Black \\
& & & $\bullet 264$ Hispanic \\
Teachers & Phone & $1-12$ & 1,008 \\
Principals & Web & $\mathrm{K}-12$ & 9,805 \\
Superintendents & Web & $\mathrm{K}-12$ & 2,307 \\
\hline
\end{tabular}


Student and parent samples were weighted to correct for unequal selection probability and nonresponse. Student data were weighted to match national demographics of age, gender, race, ethnicity and region. Parent data were weighted to match national demographics of age, gender, education, race, ethnicity and region. Demographic weighting targets were based on the most recent Current Population Survey [25].

Teacher samples were weighted to correct for unequal selection probability and nonresponse. The data were weighted to match demographics of age, gender, education, race, ethnicity and region. Demographic weighting targets were based on Gallup Inc.'s tracking information.

Principal and superintendent samples were weighted to match national demographics of school ZIP code, school enrollment size, and census region. The margin of sampling error for each population is between \pm 1.0 and \pm 3.9 percentage points at the $95 \%$ confidence level [26].

The inclusion of K-12 students as well as influencers in their education (i.e., parents and educators at various levels) provides us with a wider lens to understand the social factors for students from both the intervening perspective (from the students themselves) and the external context. We oversampled Black and Hispanic students and parents, which, along with representative samples of the U.S., allowed for comparisons among Black, Hispanic, and White populations. Other races were included in the representative sample, but their sample sizes were too small for comparisons. The representative samples also allowed us to analyze differences by gender for the students and parents.

The surveys for students, parents, teachers, and principals each lasted about 10 minutes, with $30-40$ questions. Superintendents were surveyed as part of another regular online survey, with 10 closed-ended questions for this study.

To ensure that respondents were considering CS properly, we provided them with a definition of CS at the beginning, and gave reminders with the definition multiple times throughout the survey. The definition we provided is as follows:

Computer science involves using programming/coding to create more advanced artifacts, such as software, apps, games, websites and electronics, and computer science is not equivalent to general computer use.

Surveys for all five groups covered topics on perceptions of $\mathrm{CS}$, interest in and desire for CS, in- and out-of-school opportunities for CS, participation in CS, and obstacles to providing and accessing CS opportunities. Survey items were closed-ended, with agreement for yes/no questions and Likert scales for agreement with statements (1-3 Likert for students and parents and 1-5 Likert for teachers, principals, and superintendents). Surveys were not completely the same from the first year to second year, as new questions were introduced based on findings from the first year. Many questions were retained so that trends could be tracked over the entire research study.

After data were collected, a rigorous quality assurance process was used to clean the data. The data were then coded and reviewed by response. Factors were analyzed using regression to understand trends across and within the surveyed populations and Pearson's correlation to identify relationships between variables. When analyzing differences by race or gender, income was controlled. Factors were categorized to include ability, fit, and external context as well as interest in CS.

\section{FINDINGS}

We explore our findings through the lens of our theoretical framework and delineate how they confirm some of the literature on racial/ethnic differences at a larger scale with respect to CS education while further contributing new findings, particularly on social factors at the K-12 level, and how they confirm much of the prior research on gender differences, focusing on the K-12 level. With the framework, we focus on ability, fit, and external context as factors that influence pursuit of CS, which we investigate through students' reported interest in CS.

\subsection{Ability}

We build on Lewis et al.'s framework of ability [2] by exploring it within the $\mathrm{K}-12$ context, rather than at the postsecondary level. Therefore, rather than understanding ability within the context of a CS learning experience, we examined ability through intervening conditions: students' confidence to learn $\mathrm{CS}$, their ratings of skills related to CS, and their perception of the need to be smart to do CS since most have not learned CS.

For confidence, we found that Black students were more likely to indicate that they were "very confident"' they could learn CS, with $68 \%$ saying so compared to $51 \%$ of Hispanic and $56 \%$ of White students. This is surprising given the underrepresentation of both Black and Hispanic students, yet the former have high confidence while the latter have low confidence in CS. By gender, our results confirm much of the research on confidence [e.g., 16,20-24]. We found $65 \%$ of boys said that they were "very confident" they could learn CS compared to just $48 \%$ of girls.

When looking at students' self-rated skills in math and science, results are similar to confidence in CS. While differences were negligible in math by race/ethnicity, Hispanic students were less likely to say that they were "very skilled" in science, with $36 \%$ indicating so compared to $50 \%$ of Black students and $41 \%$ of White students. We did find that students' self-rated skills in math and science were correlated with their confidence to learn CS (math PC $=0.199, \mathrm{p}<0.001$; science $\mathrm{PC}=$ $0.243, \mathrm{p}<0.001)$. Girls were less likely than boys to say they were "very skilled" in math or science, with $48 \%$ of boys saying this for each, compared with $37 \%$ of girls for math and $33 \%$ for science.

Finally, we looked at students' perception of the need to be smart as an indicator of their mindset about CS [27], as it affects students' perspectives of their ability. Over half of all students agreed that "people who do CS need to be very smart," indicating that there is a strong perception of innate or fixed ability. By race/ethnicity, we found patterns similar to confidence, with Black students least likely to agree and most likely to disagree 
that "people who do CS need to be very smart" while Hispanic students were most likely to agree and least likely to disagree (see Figure 1). However, by gender, we found no difference with $53 \%$ of both females and males agreeing with the need to be smart.

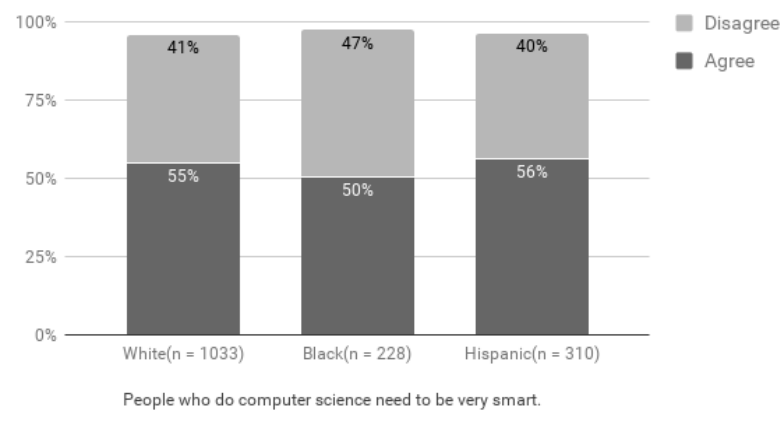

Figure 1: Student agreement with "People who do computer science need to be very smart," by race/ethnicity.

In sum, our findings indicate that Black students have greater self-perceived ability in CS. On the other hand, our results indicate that Hispanic students may not be as well supported for ability, as indicated by their weak self-assessments of the three ability items (Table 1). By gender, we found that boys had greater self-perceived ability, though we found no difference by gender in their mindset about the need to be smart.

\subsection{Fit}

Building off of the grounded theory of fit from Lewis et al.' [1], we expand to $\mathrm{K}-12$ students. In particular, we use students' selfrated skills in various subjects to determine if they identify with the singularly focused aspect of CS, in which perceptions of people in CS are that they do not have other interests. We also consider perceptions of CS and whether they fit the stereotypes of being asocial, competitive, and male. Finally, we look at how students envision their fit in CS through their indication of whether their future jobs would involve CS and whether they identify with those they see represented as practicing CS.

To understand if students who identified as skilled in math and science and not other subjects were more likely to be interested in pursuing CS, we asked students how skilled they considered themselves in math, science, English (reading and writing), music, sports, searching the Internet, and working with other people. Interestingly, by race/ethnicity, we found the Black students tended to rate their skills higher than White or Hispanic students across most areas while Hispanic students were less likely to rate their skills high (see Figure 2). Hispanic students were less likely to rate their skills in academic subjects high, and as noted above, particularly in math and science. By gender (Figure 2), also discussed above, girls are less likely than boys to say that they are "very skilled" in math or science. On the other hand, girls are more likely than boys to say that they are very skilled in English or music, with $46 \%$ of boys versus $60 \%$ of girls indicating they are "very skilled" in English and 36\% of boys versus $48 \%$ of girls indicating they are "very skilled" in music. Thus, while no pattern is apparent by race/ethnicity, there are clearer indicators by gender of the singular focus of CS playing out in terms of representation in CS.

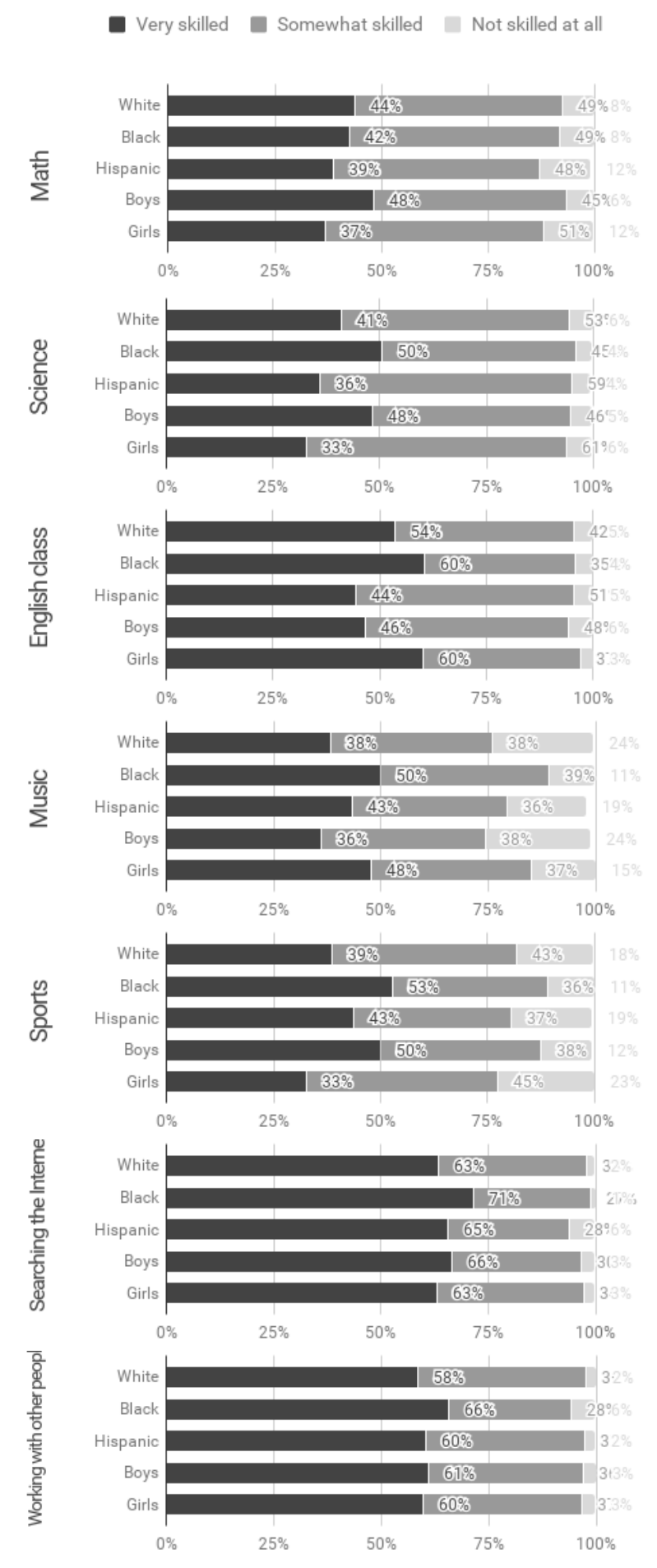

Figure 2: Students' self-rated skills in various areas, by race/ethnicity (White $\mathrm{n}=1033$, Black $\mathrm{n}=228$, Hispanic $\mathrm{n}=310$ ) and by gender (boys $n=901$, girls $n=771$ ). 
Table 3: Students' views of people engaged in computer science in the media.

\begin{tabular}{|c|c|c|c|c|c|c|}
\hline & & $\begin{array}{c}\text { White } \\
(\mathrm{n}=1033)\end{array}$ & $\begin{array}{c}\text { Black } \\
(\mathrm{n}=228)\end{array}$ & $\begin{array}{l}\text { Hispanic } \\
(\mathrm{n}=310)\end{array}$ & $\begin{array}{c}\text { Male } \\
(\mathrm{n}=901)\end{array}$ & $\begin{array}{l}\text { Female } \\
(\mathrm{n}=771)\end{array}$ \\
\hline \multirow[t]{3}{*}{ In TV shows } & Often & $20 \%$ & $34 \%$ & $23 \%$ & $25 \%$ & $21 \%$ \\
\hline & Sometimes & $62 \%$ & $44 \%$ & $54 \%$ & $55 \%$ & $61 \%$ \\
\hline & Never & $18 \%$ & $22 \%$ & $22 \%$ & $20 \%$ & $19 \%$ \\
\hline \multirow[t]{3}{*}{ In movies } & Often & $24 \%$ & $36 \%$ & $23 \%$ & $28 \%$ & $23 \%$ \\
\hline & Sometimes & $62 \%$ & $47 \%$ & $60 \%$ & $59 \%$ & $61 \%$ \\
\hline & Never & $13 \%$ & $16 \%$ & $17 \%$ & $13 \%$ & $16 \%$ \\
\hline \multirow{3}{*}{$\begin{array}{l}\text { Online through social media, articles } \\
\text { or videos }\end{array}$} & Often & $34 \%$ & $32 \%$ & $36 \%$ & $39 \%$ & $26 \%$ \\
\hline & Sometimes & $47 \%$ & $51 \%$ & $50 \%$ & $43 \%$ & $55 \%$ \\
\hline & Never & $19 \%$ & $17 \%$ & $14 \%$ & $17 \%$ & $18 \%$ \\
\hline \multicolumn{2}{|c|}{$\begin{array}{l}\text { If often or sometimes see people "doing computer } \\
\text { science" in TV, movies, or online: }\end{array}$} & $(\mathrm{n}=998)$ & $(n=217)$ & $(\mathrm{n}=299)$ & $(\mathrm{n}=870)$ & $(\mathrm{n}=744)$ \\
\hline Thinking about all of the people you & Often & $16 \%$ & $26 \%$ & $13 \%$ & $21 \%$ & $11 \%$ \\
\hline see or read about doing computer & Sometimes & $59 \%$ & $54 \%$ & $65 \%$ & $61 \%$ & $57 \%$ \\
\hline $\begin{array}{l}\text { science in TV shows, in movies or } \\
\text { online, how often do you see people } \\
\text { like you doing computer science? }\end{array}$ & Never & $25 \%$ & $20 \%$ & $22 \%$ & $18 \%$ & $31 \%$ \\
\hline
\end{tabular}

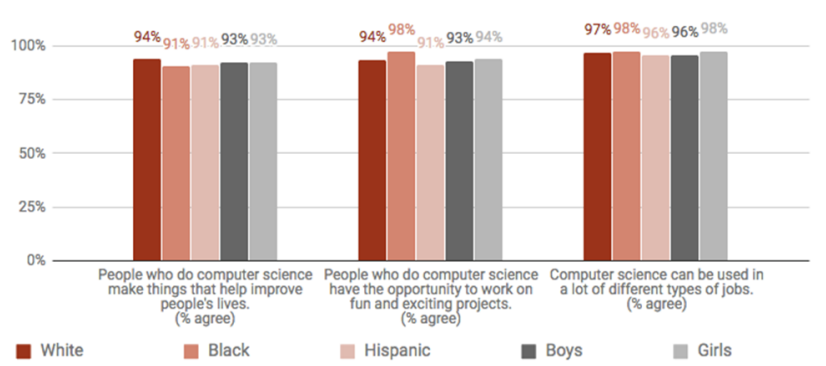

Figure 3: Students' agreement with perceptions about CS, by race/ethnicity (White $\mathrm{n}=1033$, Black $\mathrm{n}=228$, Hispanic $\mathrm{n}=310$ ) and by gender (boys $n=901$, girls $n=771$ ).

Common perceptions of CS are that the field is boring, asocial, competitive, individualistic, and male. We asked students about their agreement with various statements about CS. Surprisingly, we found very positive perceptions about the field of CS across races/ethnicities and genders, with no significant difference, with over $92 \%$ of students agreeing that CS helps improve people's lives, involves fun and exciting projects, and can be used in many different types of jobs (see Figure 3).

Finally, we examined how students envisioned their fit through their anticipated careers as well as through representations in the media. We found that by race/ethnicity, Hispanic students were more likely than White students to say that it is "very likely" that they will have a job where they will need to know CS (38\% of Hispanic students versus $26 \%$ of White students and $30 \%$ of Black students). By gender, boys were more likely to indicate that it is "very likely" they will have a job needing CS, with $35 \%$ indicating so compared to $22 \%$ of girls.

Regarding representations in the media, Black students were more likely to see people engaged in CS in TV shows and movies (Table 3). Of students who see people engaged in CS in the media, Black students were also more likely than White or Hispanic students to often see someone "like [themselves]" while
Hispanic students were least likely to often see someone "like [themselves]." By gender, girls were not only less likely than boys to see representations of CS in the media overall, of students who do see people engaged in CS in the media, girls were also less likely to often see someone "like [themselves]" ( $11 \%$ of girls versus $21 \%$ of boys) while they were more likely to never see someone "like [themselves]" (31\% of girls versus $18 \%$ of boys).

Interestingly, we found that negative perceptions of CS were low, with a large majority of all students noting very positive perceptions about CS, yet fit, as examined through alignment of identity with CS, varied by group. Overall, we found that fit for Black students was strong. For Hispanic students, it was mixed. Hispanic students indicated high likelihood to have a job needing CS but also rated their CS and related skills low and were less likely to see someone "like [themselves]" in CS in the media. By gender, boys' fit was extremely strong across all aspects we examined whereas girls' fit was weak.

\subsection{External context}

The final influencing factor we examined was external social context from the perspectives of parents and educators. We explore encouragement, parents' perceived skills of their children, perceived interest by demographic, knowing a role model in the field, and parents' and educators' mindsets.

For encouragement, we explored whether students have been told by a teacher or parent that they would be good at CS, finding no significant difference by race/ethnicity. However, we found that boys were more likely than girls to say that they have been told by a teacher or parent that they would be good at CS. In fact, $39 \%$ and $46 \%$ of boys said they have been told this by a teacher or parent, respectively, compared to $26 \%$ and $27 \%$ of girls. Not surprisingly, we found that while there is no difference in parents' rating of their child's skills in math or science by the children's genders, parents were more likely to say that girls are more skilled in English (reading and writing), 
music, and working with others, with $70 \%$ of parents of girls versus $49 \%$ of parents of boys indicating their child is "very skilled" in English, $46 \%$ of parents of girls versus $34 \%$ of parents of boys indicating their child is "very skilled" in music, and $69 \%$ of parents of girls versus $59 \%$ of parents of boys indicating their child is "very skilled" in working with other people.

When looking at perceived interest, parents of Black and Hispanic children were actually more likely than parents of White children to think that their children are "very interested" in learning CS (26\% of parents of White children, $32 \%$ of parents Black children, and $42 \%$ of parents of Hispanic children; see Figure 4) while parents of boys were more likely than parents of girls to say so ( $37 \%$ versus $25 \%$, respectively). This follows from students' reported encouragement. Adults may be more likely to support students who they believe are interested. In fact, parents of boys were more likely to want their children to learn CS than parents of girls ( $91 \%$ versus $83 \%)$. Similarly, Black and Hispanic parents were more likely to say that they want their children to learn CS, with $92 \%$ indicating so compared $84 \%$ of White parents.

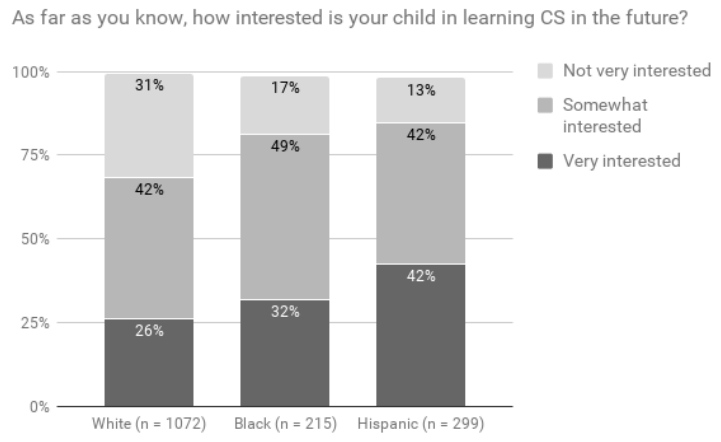

Figure 4: Parents' perceptions of their children's interest in learning CS, by race/ethnicity of child.

Furthermore, when asked about why certain groups (women, Blacks, and Hispanics) are underrepresented in CS, parents were slightly more likely to cite lack of interest and motivation compared to educators while teachers were more likely to cite lack of opportunity and exposure. This implies that parents may be more likely to believe that underrepresented students are opting out of engaging in CS rather than facing external barriers.

Another piece of the external context is whether students know adults who work in the field. When asked about if they know someone "who works with computers or other types of technology," Hispanic students were least likely to say they do, with $49 \%$ saying so compared to $68 \%$ of White students and $65 \%$ of Black students. By gender, there was no difference with $63 \%$ of boys and girls saying that they know an adult in the field.

Finally, the adults' mindsets along with how they perceive students may determine how they support students. Among parents, we found similar trends to students by demographic in their agreement with "people who do computer science need to be very smart," with $47 \%$ of parents of Black children, $56 \%$ of parents of Hispanic children, and $51 \%$ of parents of White children agreeing. We also found that females were more likely to disagree, with $47 \%$ of female parents versus $43 \%$ of male parents disagreeing and $19 \%$ of female teachers versus $12 \%$ of male teachers disagreeing (Figure 5).

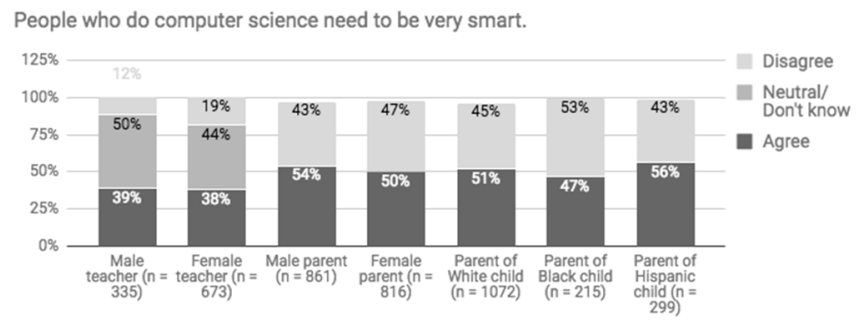

Figure 5: Adults' perceptions of the need to be smart to do computer science, by teacher and parent gender and by parent race/ethnicity.

In summary, the external social context is mixed for Black and Hispanic students in that while they and their parents are more likely to value and be interested in CS, Hispanic students are less likely to know someone in the field and they and their parents are more likely to believe people doing CS need to be very smart. On the other hand, boys are well supported in the external social context, with greater encouragement as well as greater perceived CS and relevant skills and interest.

\subsection{Interest}

Based on the theoretical framework [1,2], ability, fit, and external context have been found to be key indicators for students' interest in pursuing CS among college students. We expand this to $\mathrm{K}-12$ students, specifically in middle and high schools, to understand indicators of which groups are, or are not, socially supported in CS. By race/ethnicity, we found mixed indicators with Black students having greater self-perceived ability, stronger fit via identity with CS, and more supportive external social contexts while Hispanic students had low selfperceived ability, mixed fit, and mixed support in their external social contexts. These social factors point to complex barriers, as both of these groups continue to be underrepresented in the CS field. In contrast, by gender, the indicators were much more straightforward in that girls had low self-perceived ability, weak fit, and less supportive external contexts, and correspondingly are underrepresented in CS.

To explore possible outcomes from these indicators, we asked students about their interest in learning CS. We found that students' interest was correlated with confidence $(\mathrm{PC}=0.397, \mathrm{p}$ $<0.001$ ) and encouragement from teachers and parents (teachers $\mathrm{PC}=0.313, \mathrm{p}<0.001$; parents $\mathrm{PC}=0.360, \mathrm{p}<0.001)$, components of ability and external context. We also found that interest was correlated with students' reported likelihood to have a job needing CS $(\mathrm{PC}=0.422, \mathrm{p}<0.001)$, a component of fit. Therefore, components of each of the input categories from the theoretical framework [1,2], ability, fit, and external context, 
are confirmed by our study to be correlated with interest in learning CS.

We found that Black students and Hispanic students were more likely than White students to say that they are "very interested" in learning CS, with $31 \%$ of Black students, $35 \%$ of Hispanic students, and $21 \%$ of White students saying so. This follows from our exploration of social indicators of ability, fit, and external context for Black students, while the mixed social indicators for Hispanic students may have certain components that are stronger, contributing to Hispanic students' greater interest.

Given the strong social indicators by gender, it is not surprising that we found that boys were over twice as likely as girls to say that they were "very interested" in learning CS (34\% of boys versus $16 \%$ of girls) and that girls were almost twice as likely as boys to say that they were "not at all interested" (13\% of boys versus $24 \%$ of girls).

\section{LIMITATIONS}

While we categorize students into male or female and Black, Hispanic, or White, it is important to understand that the differences are based on the distributions of the entire groups. Therefore, there are always individuals who are outliers or deviate from the mean and we must therefore be careful not to overgeneralize the findings. When working with students, it is key to view them as individuals and with empathy towards their unique backgrounds [28-31].

Furthermore, we only examined differences between males and females and between Black, Hispanic, and White students and did not look at groups outside of these categories due to small sample sizes. Additionally, while the intersections between gender and race/ethnicity are important and involve unique social perceptions, their small sample sizes would have yielded results with high margins of error, and we wanted to be careful to not draw conclusions from these types of results.

Finally, as a quantitative survey study, we were limited to what we asked and were not able to collect information beyond our questions. There are many factors that we were not able to consider that may have large contributions to students' interest to pursue CS. Additionally, while we defined CS at the beginning and reminded respondents multiple times throughout our survey, there is still the possibility that their understanding of CS differed from the definition we provided.

\section{SIGNIFICANCE}

The theoretical framework from Lewis et al. [1,2] provided a lens to explore why students choose to pursue or not pursue CS. We built on their work with an exploration of what is happening quantitatively by demographic, at a national scale, for the factors of ability, fit, and external context. We confirmed that components of these factors correlate with interest in learning CS. We built on and confirmed much of the previous research on factors influencing gender gaps. We also fill in gaps in the literature with new analyses of social factors by race/ethnicity.

The implication of our work is the need to consider both structural and social factors. Our findings indicate that different supports are needed for each group. While we found that Black students have greater self-perceived ability, stronger fit, and more supportive external social contexts, and are more likely to be very interested in CS, they continue to be underrepresented. Their high confidence as well as lower agreement with the mindset that one needs to be smart to do CS also point towards what should be greater representation. Other research [e.g., 3] found that Black students have lower access to CS learning opportunities. Thus, structural barriers may be greater. We hypothesize that the high confidence and ratings may be the result of minimal access to more advanced CS activities [26], and students may not know their actual abilities and overestimate their abilities. Along with increasing access, efforts should focus on supporting these social factors and ensuring new exposure does not discourage students.

Furthermore, we found that the factors are mixed for Hispanic students, who, along with their parents, appear to value CS and envision its importance to their future careers, yet they are less likely to know a role model in tech or identify with those represented as engaging in CS in the media and are less confident in their CS and related skills. Confidence has been found to be correlated with persistence [32], so Hispanic students' low confidence should be of major concern to efforts that support this population. Other research [e.g., 3] found that Hispanic students have lower exposure to computers. Similar to Black students, these structural barriers may contribute to Hispanic students' lower participation. Teachers of Black and Hispanic students should find ways to support their greater interest.

Finally, girls' underrepresentation aligns with our findings on ability, fit, and external context, which confirm bodies of work in this area. The challenge here is that girls have lower interest in learning CS, which may cause their influencers to view that as an independent choice. However, our research highlights that this interest is correlated with confidence, encouragement, and perceived likelihood to need CS for their careers. Therefore, encouragement could change a girl's interest. Efforts should focus on supporting influencers around girls and changing perceptions about who does and does not belong in CS.

To ensure that all students are enabled to learn CS, it is not enough to focus solely on providing access nor is it enough to focus solely on positive campaigns around CS. Our paper indicates that factors are much more complex and a holistic approach towards equity should be taken, in which all factors are considered and engagement is catered to each individual's circumstances. We believe that the research detailed in this paper builds upon and contributes to the body of knowledge regarding how social factors play out for different demographics before college and can therefore help to inform efforts to broaden access to $\mathrm{CS}$ at the $\mathrm{K}-12$ level.

\section{ACKNOWLEDGMENTS}

The authors would like to acknowledge the contributions of many of our colleagues at Google and Gallup. 


\section{REFERENCES}

[1] Lewis, Colleen M., Ruth E. Anderson, and Ken Yasuhara. 2016. I Don't Code All Day: Fitting in Computer Science When the Stereotypes Don't Fit. In Proceedings of the 2016 ACM Conference on International Computing Education Research, 23-32. ACM, 2016.

[2] Lewis, Colleen M., Ken Yasuhara, and Ruth E. Anderson. 2011. Deciding to major in computer science: a grounded theory of students' self-assessment of ability. In Proceedings of the seventh international workshop on Computing education research, 3-10. ACM, 2011.

[3] Google Inc. \& Gallup. 2016. Trends in the State of Computer Science in U.S. K12 Schools. Retrieved from http://goo.gl/j291E0.

[4] Margolis, Jane, Rachel Estrella, Joanna Goode, Jennifer Jellison Holme, and Kim Nao. 2010. Stuck in the shallow end: Education, race, and computing. MIT Press, 2010.

[5] Susan Colby, Helen Ma, Kelsey Robinson, and Lareina Yee. 2016. What It Will Take to Make the Tech Industry More Diverse. Harvard Business Review.

[6] Victoria J. Rideout, Kimberly A. Scott, and Kevin A. Clark. 2016. The Digital Lives of African American Tweens, Teens, and Parents: Innovating and Learning with Technology. (Fall 2016). Retrieved April 1, 2017 from https://cgest.asu.edu/sites/default/files/digital_lives_report_0.pdf.

[7] Lori Carter. 2006. Why students with an apparent aptitude for computer science don't choose to major in computer science. ACM SIGCSE Bulletin 38, 1 (2006), 27-31.

[8] Tor Busch. 1995. Gender differences in self-efficacy and attitudes toward computers. Journal of educational computing research 12, 2 (1995), 147-158.

[9] Anne-Kathrin Peters and Arnold Pears. 2013. Engagement in Computer Science and IT--What! A Matter of Identity?. In Learning and Teaching in Computing and Engineering (LaTiCE), 2013, 114-121. IEEE, 2013.

[10] Tamar Levine and Smadar Donitsa-Schmidt. 1998. Computer use, confidence, attitudes, and knowledge: A causal analysis. Computers in human behavior 14, 1 (1998), 125-146.

[11] Allison Master, Sapna Cheryan, and Andrew N. Meltzoff. 2016. Computing whether she belongs: Stereotypes undermine girls' interest and sense of belonging in computer science. Journal of Educational Psychology 108, 3 (2016), 424.

[12] Linda J. Sax, Kathleen J. Lehman, Jerry A. Jacobs, M. Allison Kanny, Gloria Lim, Laura Monje-Paulson, and Hilary B. Zimmerman. 2017. Anatomy of an enduring gender gap: The evolution of women's participation in computer science. The fournal of Higher Education 88, no. 2 (2017), 258-293.

[13] Amanda B. Diekman, Elizabeth R. Brown, Amanda M. Johnston, and Emily K. Clark. 2010. Seeking congruity between goals and roles: A new look at why women opt out of science, technology, engineering, and mathematics careers. Psychological Science 21, 8 (2010), 1051-1057. doi:10.1177/0956797610377342.

[14] Jacquelynne S. Eccles. 2007. Where Are All the Women? Gender Differences in Participation in Physical Science and Engineering. In S. Ceci (Ed); Williams, Wendy M. (Ed). (2007). Why aren't more women in science?: Top researchers debate the evidence, (pp. 199-210). Washington, DC, US: American Psychological Association, xx, $254 \mathrm{pp}$

[15] David C. Webb and Susan B. Miller. 2015. Gender analysis of a large scale survey of middle grades students' conceptions of computer science education. In Proceedings of the Third Conference on GenderIT, 1-8. ACM, 2015.

[16] Jill Denner, Linda Werner, Lisa O'Connor, and Jill Glassman. 2014. Community college men and women: A test of three widely held beliefs about who pursues computer science. Community College Review 42, 4 (2014), 342362 .
[17] Monica M. McGill, Adrienne Decker, and Amber Settle. 2016. Undergraduate Students' Perceptions of the Impact of Pre-College Computing Activities on Choices of Major. ACM Transactions on Computing Education (TOCE) 16, no. 4 (2016), 15.

[18] Mark Guzdial, Barbara J. Ericson, Tom McKlin, and Shelly Engelman. 2012. A statewide survey on computing education pathways and influences: Factors in broadening participation in computing. In Proceedings of the 9th Annual International Conference on International Computing Education Research (ICER'12). ACM, New York, NY, 143-150. http://doi.acm.org/10.1145/2361276.2361304.

[19] Joanna Goode, Rachel Estrella, and Jane Margolis. 2006. Lost in translation: Gender and high school computer science. na, 2006.

[20] Joanne M. Badagliacco. 1990. Gender and race differences in computing attitudes and experience. Social Science Computer Review 8, 1 (1990), 42-63.

[21] Thomas J. Smith, Spencer L. Pasero, and Cornelius M. McKenna. 2014. Gender effects on student attitude toward science. Bulletin of Science, Technology \& Society 34, 1-2 (2014), 7-12.

[22] Yuk Fai Cheong, Frank Pajares, and Paul S. Oberman. 2004. Motivation and academic help-seeking in high school computer science. Computer Science Education 14, 1 (2004), 3-19.

[23] Heather Dryburgh. 2000. Underrepresentation of girls and women in computer science: Classification of 1990s research. Fournal of educational computing research 23, 2 (2000), 181-202.

[24] Allan Fisher, Jane Margolis, and Faye Miller. 1997. Undergraduate women in computer science: experience, motivation and culture. In ACM SIGCSE Bulletin, vol. 29, 1, pp. 106-110. ACM, 1997.

[25] United States Census Bureau. 2016. Current Population Survey. Retrieved from https://www.census.gov/programs-surveys/cps.html.

Google Inc. \& Gallup. 2016. Diversity Gaps in Computer Science: Exploring the Underrepresentation of Girls, Blacks and Hispanics. Retrieved from http://goo.gl/PG34aH.

[26] Google Inc. \& Gallup. 2016. Diversity Gaps in Computer Science: Exploring the Underrepresentation of Girls, Blacks and Hispanics. Retrieved from http://goo.gl/PG34aH.

[27] Carol S. Dweck. 2008. Mindset: The new psychology of success. Random House Digital, Inc., 2008.

[28] Irene V. Blair. 2002. The malleability of automatic stereotypes and prejudice. Personality and Social Psychology Review 6, 3 (2002), 242-261.

[29] Molly Carnes, Patricia G. Devine, Linda Baier Manwell, Angela ByarsWinston, Eve Fine, Cecilia E. Ford, Patrick Forscher, Carol Isaac, Anna Kaatz, Wairimu Magua, Mari Palta, and Jennifer Sheridan. 2015. Effect of an intervention to break the gender bias habit for faculty at one institution: a cluster randomized, controlled trial. Academic medicine: journal of the Association of American Medical Colleges 90, 2 (2015), 221.

[30] Sarah M. Jackson, Amy L. Hillard, and Tamera R. Schneider. 2014. Using implicit bias training to improve attitudes toward women in STEM. Social Psychology of Education 17, 3 (2014), 419-438.

[31] Jason A. Okonofua, David Paunesku, and Gregory M. Walton. 2016. Brief intervention to encourage empathic discipline cuts suspension rates in half among adolescents." Proceedings of the National Academy of Sciences (2016). doi: 10.1073/pnas.1523698113.

[32] Robert W. Lent, Steven D. Brown, and Kevin C. Larkin. 1984. Relation of selfefficacy expectations to academic achievement and persistence. Fournal of counseling psychology 31, 3 (1984), 356. 